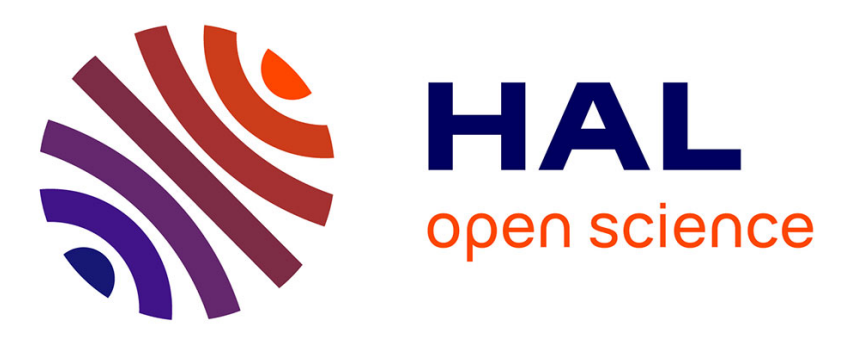

\title{
Effect of different fluxes on the morphology of the LaPO4: Ce, Tb phosphor
}

Frédéric Duault, Michel Junker, Philippe Grosseau, Bernard Guilhot, Philibert Iacconi, Bernard Moine

\section{- To cite this version:}

Frédéric Duault, Michel Junker, Philippe Grosseau, Bernard Guilhot, Philibert Iacconi, et al.. Effect of different fluxes on the morphology of the LaPO4: Ce, Tb phosphor. Powder Technology, 2005, 154(2-3), pp.132-7. 10.1016/j.powtec.2005.04.037 . hal-00008922

\section{HAL Id: hal-00008922 \\ https://hal.science/hal-00008922}

Submitted on 20 Sep 2005

HAL is a multi-disciplinary open access archive for the deposit and dissemination of scientific research documents, whether they are published or not. The documents may come from teaching and research institutions in France or abroad, or from public or private research centers.
L'archive ouverte pluridisciplinaire HAL, est destinée au dépôt et à la diffusion de documents scientifiques de niveau recherche, publiés ou non, émanant des établissements d'enseignement et de recherche français ou étrangers, des laboratoires publics ou privés. 


\title{
EFFECT OF DIFFERENT FLUXES ON THE MORPHOLOGY OF THE $\mathrm{LaPO}_{4}: \mathrm{Ce}$, Tb PHOSPHOR
}

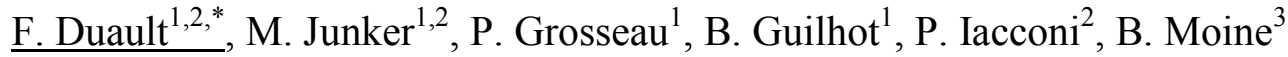 \\ 1-Centre SPIN, département PC2M, CNRS UMR 5148, Ecole Nationale Supérieure des Mines \\ de Saint Etienne, 158 cours Fauriel, F-42023 Saint Etienne, Cedex 2. \\ *duault@emse.fr \\ 2-LPES-CRESA, EA1174, Université de Nice-Sophia Antipolis, Parc Valrose, F-06108, Nice \\ Cedex 2
}

3-LPCML, Université Claude Bernard Lyon I, 10 rue AM Ampère 69622 Villeurbanne Cedex

\begin{abstract}
LaPO}_{4}: \mathrm{Ce}, \mathrm{Tb}(\mathrm{LaCeT})$ is a green phosphor used in fluorescent lamps and plasma display panels. In order to improve the fabrication process of this phosphor, different fluxes have been used. Their influence on the particles size and shape is described thanks to SEM analyses.

Fluxes were found to control the morphology of particles : LaCeT particles, from spherical to parallelepiped-like shape, with suitable sizes, from 0.1 to $10 \mu \mathrm{m}$, have been synthesized. Furthermore the photoluminescence emission of the obtained powders has been checked, and it has been proved that the effect of the fluxes studied is not harmful to the LaCeT final optical properties.
\end{abstract}

\section{KEY-WORDS}

Phosphor - Morphology - Particles size - Shape - Control

\section{INTRODUCTION}

Phosphors are widely used in displays and lighting devices. Morphology of phosphors (shape and size of the powder particles) is one of the key-parameters of their industrial application [1-2]. Improvement of the morphology control is of great interest and different ways are tried in order to achieve this aim [1-3]. In fact, size and shape of the phosphor particles have an important influence on the emission intensity and the efficiency of the device [4].

Phosphor particles should be non-aggregated and their particles size distribution should range between 1 to $8 \mu \mathrm{m}$ depending on the application. This morphology is required for the coating technique, which enhances the compactness of the powder and thus, the brightness of the device $[1,4]$.

$\mathrm{LaPO}_{4}: \mathrm{Ce}, \mathrm{Tb}(\mathrm{LaCeT})$, is a green phosphor which fluorescent lamps (FL) is the main application. In order to coat the lamps surface, the inside of the tube is put into contact with a suspension containing the LaCeT powder [5]. So, the phosphor grains should have a size as homogeneous as possible and above all without any aggregates nor agglomerates. Otherwise dispersion and sedimentation problems could occur. Moreover an optimal compactness of the powder is suitable in order to enhance the brightness of the display and to enable to lower the production cost.

In order to improve the efficiency of the phosphors, the surface particles should also be as smooth as possible and a high crystallization degree is required.

In the industry, phosphors are generally elaborated from oxides or carbonates by a solid state reaction : a high temperature heat treatment with or without fluxes. But this synthesis method does not allow an efficient control of the chemical homogeneity, neither the morphology of the phosphor particles without a grinding step, harmful to its optical properties $[2,6]$.

The use of precursors elaborated by the wet method (rare earth phosphates, rare earth borates,...), has been a breakthrough for the control of the phosphor particles size distribution. In order to control the particles morphology, fluxes as $\mathrm{Li}_{3} \mathrm{PO}_{4}, \mathrm{Li}_{2} \mathrm{CO}_{3}, \mathrm{~K}_{2} \mathrm{CO}_{3}, \mathrm{MgF}$, are added to the phosphor precursor and then the powder is fired at high temperature $[1,7]$. This 
method has been optimized for the LaCeT synthesis [5] without being harmful to the essential optical properties for its application fields $[5,10]$.

In other fields, such as crystal growth, some fluxes have been found to be helpful to modify the shape of crystals $[8,9]$. Furthermore the solubility of the crystalline phase into the liquid flux has been identified as a key parameter [11].

This paper deals with the elaboration of the LaCeT phosphor thanks to the interaction between a precursor chemically homogeneous and with a controlled particles size distribution with different fluxes : $\mathrm{Li}_{3} \mathrm{PO}_{4}, \mathrm{Li}_{2} \mathrm{CO}_{3}, \mathrm{Na}_{2} \mathrm{CO}_{3}, \mathrm{~K}_{2} \mathrm{CO}_{3}$.

\section{EXPERIMENTAL}

The LaCeT powder is obtained from a precursor, synthesized by coprecipitation method, by the Rhodia society.

The precursor rare earth composition, given in table 1, will be kept constant in all the further experiments.

\begin{tabular}{ccc}
\hline $\mathrm{La}$ & $\mathrm{Ce}$ & $\mathrm{Tb}$ \\
\hline $1-\mathrm{x}-\mathrm{y}=0.57$ & $\mathrm{x}=0.29$ & $\mathrm{y}=0.14$ \\
\hline Table 1. Composition of $\mathrm{La}_{1-x-y} \mathrm{Ce}_{x} \mathrm{~Tb}_{y} \mathrm{PO}_{4}$.
\end{tabular}

The LaCeT precursor is a white powder constituted of $5 \mu \mathrm{m}$ agglomerates, themselves constituted by spherical particles of 0.1 to $0.2 \mu \mathrm{m}$ diameter (Fig. 1.).

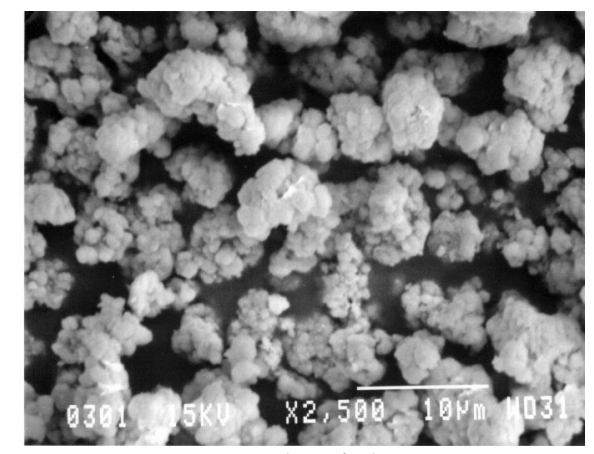

Fig. 1. SEM Micrograph of the LaCeT precursor.

The flux and the precursor are mixed together in a solvent : after having added the respective mass of precursor and flux in a beaker filled with anhydrous ethanol, the suspension is heated and mixed under magnetic agitation until all the solvent is evaporated. Then, the obtained powder is put in an alumina crucible and it undergoes the heat treatment shown on Fig. 2.

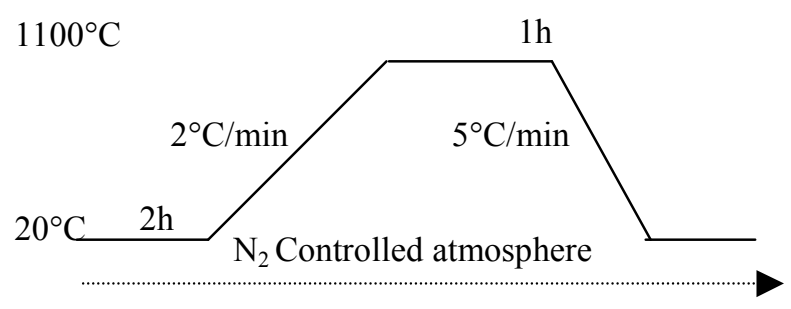

Fig. 2. Heat treatment used.

The fluxes used here are $\mathrm{Li}_{3} \mathrm{PO}_{4}, \mathrm{Li}_{2} \mathrm{CO}_{3}, \mathrm{Na}_{2} \mathrm{CO}_{3}$ and $\mathrm{K}_{2} \mathrm{CO}_{3}$. The introduced quantity of flux ranges between 0.5 to 3 weight percent of the whole rare hearth.

The shape and size of the grains were observed using a scanning electron microscope JEOL JSL-840. 
The thermoluminescence (TL) were carried out in a secondary vacuum chamber from the liquid nitrogen temperature (LNT) to $50^{\circ} \mathrm{C}$. Cooled down at LNT the sample of $2 \mathrm{mg}$ is irradiated by X-rays $(45 \mathrm{kV}, 2 \mathrm{~mA}$ with an air kerma rate of $0.035 \mathrm{~Gy} / \mathrm{min}$, during $10 \mathrm{~min})$. Then it was heated up to $50^{\circ} \mathrm{C}$ with a rate of $30 \mathrm{~K} \cdot \mathrm{m}^{-1}$. The TL curves were registered with an S13 response photomultiplier (Philips 2018B).

Excitation and emission spectra of fluorescence were achieved at a room temperature in the spectral range between 300 to $700 \mathrm{~nm}$, with the spectral emission resolution of about $1 \mathrm{~nm}$. The experimental apparatus is made up of a $500 \mathrm{~W}$ xenon lamp and two Jobin-Yvon HR 25 monochromators (one is used for excitation, and the other for the emission spectral analysis. Besides appropriate filters were used. The fluorescence detector is a Hamamatsu R928 photomultiplier with an UV-multialkali photocathode $(185-900 \mathrm{~nm})$. A constant mass of powder is inserted in the specimen carrier and a quartz window closes the chamber, compacting the powder.

\section{RESULTS}

\section{Influence of the flux cation on the phosphor morphology}

Figures 3 to 6 show SEM micrographs of the LaCeT phosphor obtained from mixtures of the precursor with the fluxes, respectively $\mathrm{Li}_{3} \mathrm{PO}_{4}, \mathrm{Li}_{2} \mathrm{CO}_{3}, \mathrm{Na}_{2} \mathrm{CO}_{3}$ and $\mathrm{K}_{2} \mathrm{CO}_{3}$, fired with the previously described protocol. The flux quantity is in each cases of $1 \mathrm{wt} \%$.

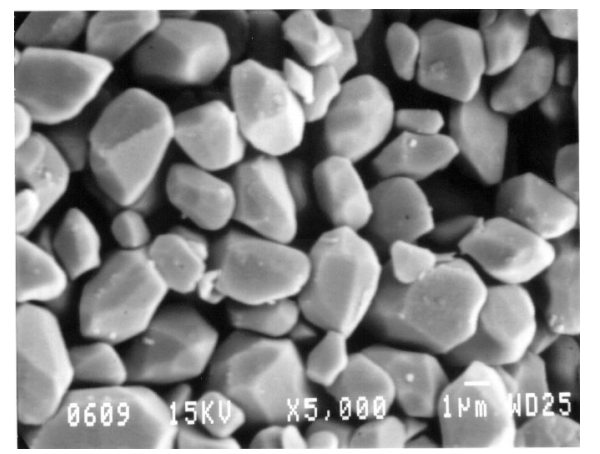

(a) $\mathrm{LaCeT}$, with $1 \mathrm{wt} \% \mathrm{Li}_{3} \mathrm{PO}_{4}\left(1000^{\circ} \mathrm{C}\right)$

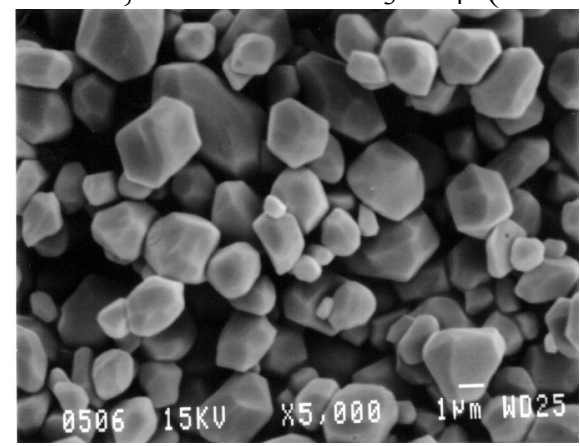

(c) $\mathrm{LaCeT}$, with $1 \mathrm{wt} \% \mathrm{Na}_{2} \mathrm{CO}_{3}\left(1000^{\circ} \mathrm{C}\right)$

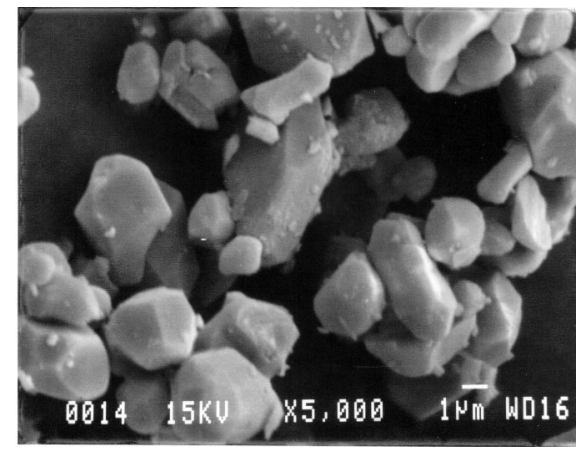

(b) $\mathrm{LaCeT}$, with $1 \mathrm{wt} \% \mathrm{Li}_{2} \mathrm{CO}_{3}\left(1000^{\circ} \mathrm{C}\right)$

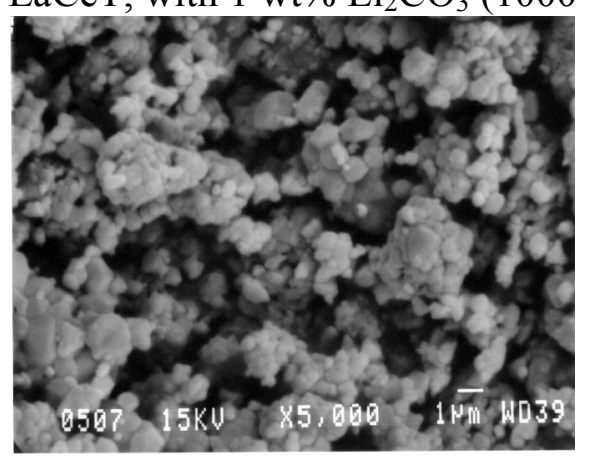

(d) $\mathrm{LaCeT}$, with $1 \mathrm{wt} \% \mathrm{~K}_{2} \mathrm{CO}_{3}\left(1000^{\circ} \mathrm{C}\right)$

Fig. 3. SEM micrographs of LaCeT after firing prepared with $1 \mathrm{wt} \%$ of several fluxes.

$\mathrm{Li}_{3} \mathrm{PO}_{4}$ and $\mathrm{Li}_{2} \mathrm{CO}_{3}$ fluxes (Fig. $3 \mathrm{a}$ and $3 \mathrm{~b}$ ) lead to the formation of regular and faceted particles of phosphors of 3-4 $\mu \mathrm{m}$ diameters. When $\mathrm{Na}_{2} \mathrm{CO}_{3}$ is added, Fig. $3 \mathrm{c}$, the obtained particles have the same shape but they are smaller. Finally, using $\mathrm{K}_{2} \mathrm{CO}_{3}$ flux (Fig. $3 \mathrm{~d}$ ), the phosphor particles have actually a smaller size, below $1 \mu \mathrm{m}$, but some agglomerates are conserved.

It seems that the type of cation added to the precursor plays an important role during the formation of the final phosphor. In fact, the smaller the diameter of the cation is, the bigger are the LaCeT particles. 
That kind of effect is probably the consequence of the diffusion of the cation into the host matrix of the phosphate during the heat treatment.

\section{Influence of the flux quantity on the phosphor morphology}

Influence of the weight percent of $\mathrm{Li}_{2} \mathrm{CO}_{3}$ added to the precursor, on the final morphology of the $\mathrm{LaCeT}$, has been studied. Micrographs of the obtained samples are reported on figure 4.

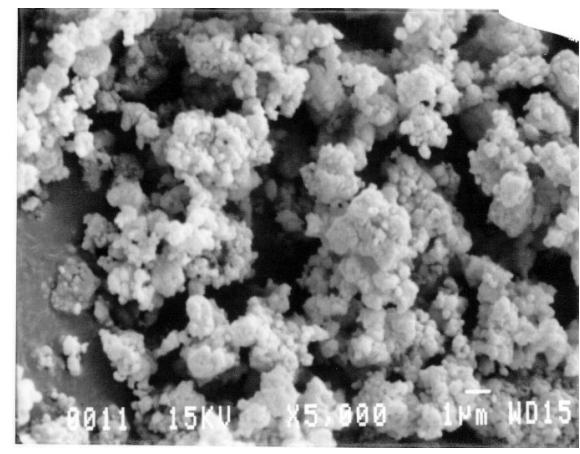

(a) $0 \mathrm{wt} \% \mathrm{Li}_{2} \mathrm{CO}_{3}$

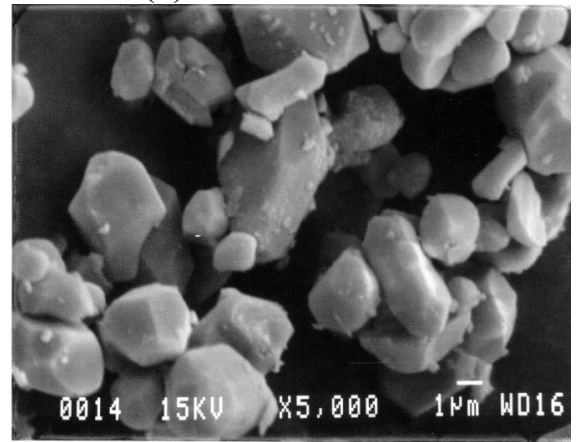

(c) $1 \mathrm{wt} \% \mathrm{Li}_{2} \mathrm{CO}_{3}$

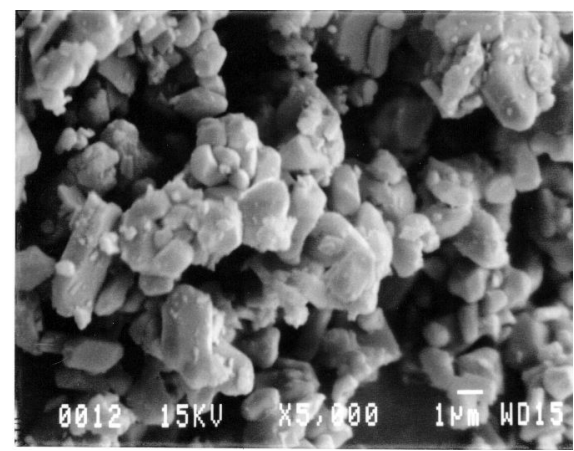

(b) $0.5 \mathrm{wt} \% \mathrm{Li}_{2} \mathrm{CO}_{3}$

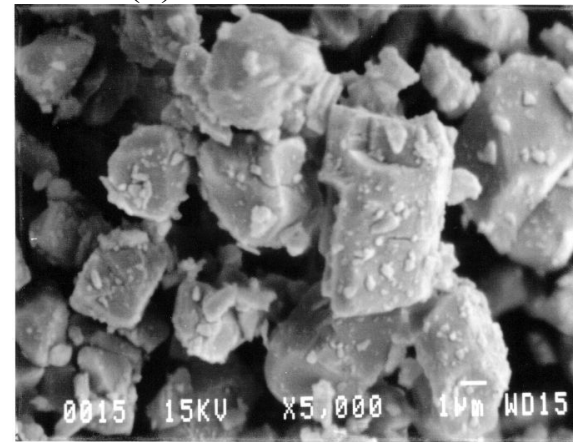

(d) $2 \mathrm{wt} \% \mathrm{Li}_{2} \mathrm{CO}_{3}$

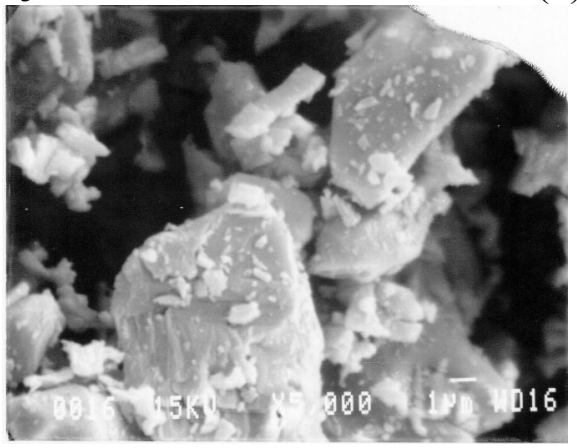

(e) $3 \mathrm{wt} \% \mathrm{Li}_{2} \mathrm{CO}_{3}$

Fig. 4. SEM micrographs of LaCeT prepared with several weight percent of $\mathrm{Li}_{2} \mathrm{CO}_{3}$ after firing.

The main characteristics of those samples are reported into table 2.

These figures show that the more $\mathrm{Li}_{2} \mathrm{CO}_{3}$ is added, the bigger are the powder particles. Furthermore, below $1 \mathrm{wt} \%$ of $\mathrm{Li}_{2} \mathrm{CO}_{3}$, particles seem to form agglomerates which is not the case for more important quantity of flux. 


\begin{tabular}{ccc}
\hline $\begin{array}{c}\mathrm{Li}_{2} \mathrm{CO}_{3} \\
\text { weight percent }\end{array}$ & $\begin{array}{c}\text { Mean particles } \\
\text { size in } \mu \mathrm{m}\end{array}$ & General observation \\
\hline 0 & 0.1 & Spherical shaped \\
\hline 0.5 & $0.5-2$ & Quasi spherical shape with facets, many aggregates \\
\hline 1 & $2-4$ & Quasi spherical shape with many facets \\
\hline 2 & $4-7$ & Parallelepiped shape with many little fragments on the \\
surface
\end{tabular}

Table 2. Influence of the $\mathrm{Li}_{2} \mathrm{CO}_{3}$ weight percent on the LaCeT particles morphology.

Regarding the particles morphology, the effect of the flux is also related to its quantity. Indeed, the particles shape goes from aggregates to quasi spherical with 0.5 and $1 \mathrm{wt} \%$ and then to parallelepiped-like with 2 and $3 \mathrm{wt} \%$.

The addition of $\mathrm{Li}_{2} \mathrm{CO}_{3}$ flux to precursor leads to a morphological modification, for both the shape and size of the final phosphor, which is function of the flux weight percent.

\section{Thermoluminescence}

The TL curves were carried out as described above, on a sample free of flux and an other with $1 \mathrm{wt} \% \mathrm{Li}_{2} \mathrm{CO}_{3}$ prepared in optimal conditions $\left(1100^{\circ} \mathrm{C}\right.$ under $\mathrm{Ar}+\mathrm{H}_{2} 1 \%$ for $\left.1 \mathrm{~h}\right)$. The results are shown in the Fig.5. As we have already shown [12], the glow curves of the LaCeT are characterized by three peaks. The first two one, at $-115^{\circ} \mathrm{C}$ and $-80^{\circ} \mathrm{C}$ can be found with a slightly higher intensity on the curve (b) than (a) and the third peak, at $-35^{\circ} \mathrm{C}$ is four times higher when $1 \mathrm{wt} \%$ of flux is used and a bit shifted to $-20^{\circ} \mathrm{C}$.

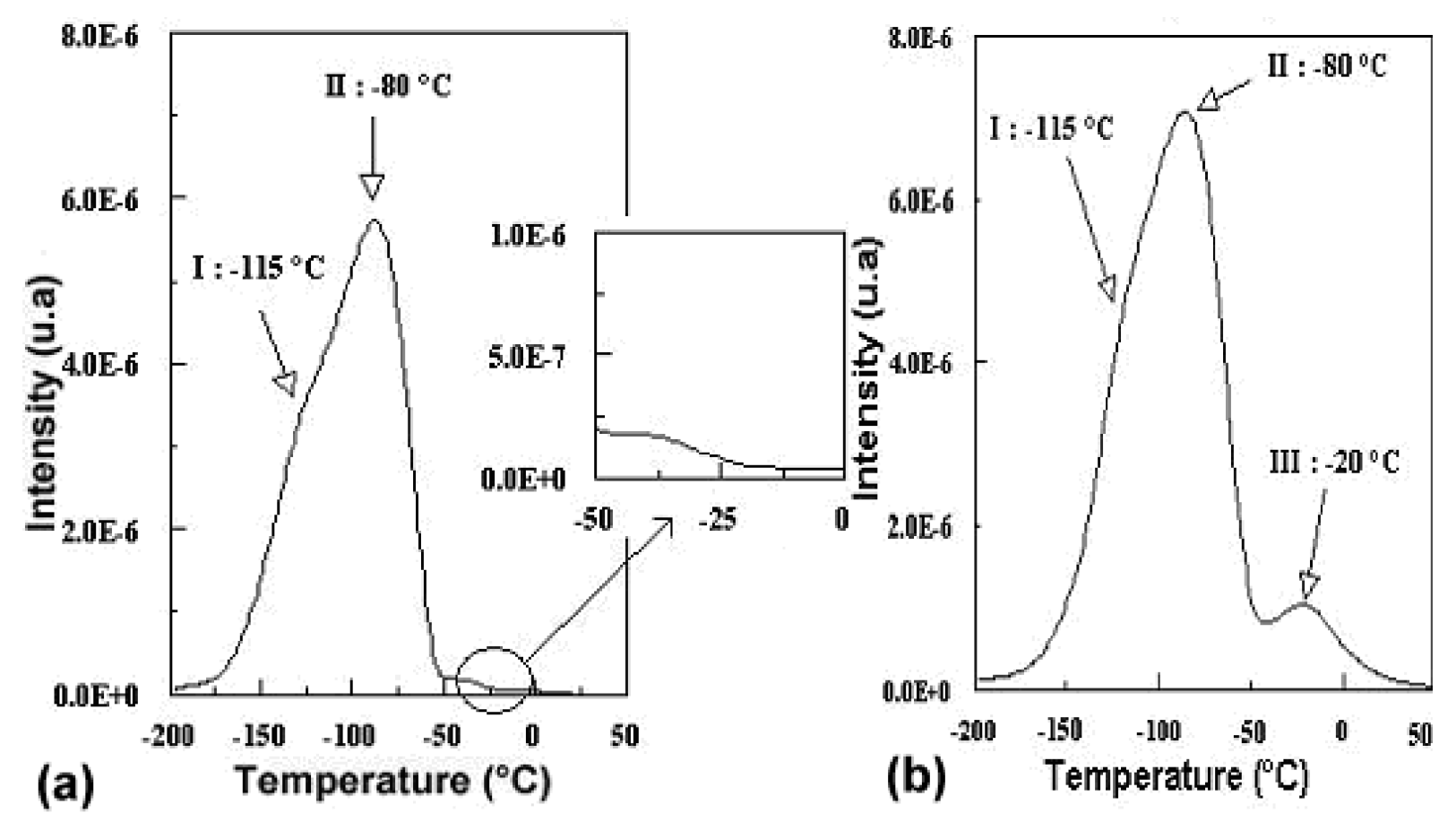


Fig. 5. TL curves obtained from : (a) LaCeT without flux and (b) $\mathrm{LaCeT}$ with 1 wt\% of $\mathrm{Li}_{2} \mathrm{CO}_{3}$ after $X$-ray irradiation at LNT $(0.35 G y)$.

That means that the LaCeT crystalline matrix has three types of trap defects and that the add of $\mathrm{Li}_{2} \mathrm{CO}_{3}$ increases the concentration of these defects. This phenomenon is explained by the diffusion of $\mathrm{Li}$ in the crystalline matrix of the LaCeT.

\section{Diffuse reflection spectra, emission intensity and yield}

The diffuse reflection spectra of the samples prepared with fluxes in optimal conditions $\left(1100^{\circ} \mathrm{C}\right.$ under $\mathrm{Ar}+\mathrm{H}_{2} 1 \%$ or $\mathrm{N}_{2}$ for $1 \mathrm{~h}$ ) and without fluxes (Fig. 6) do not show any difference as Junker has shown [5].

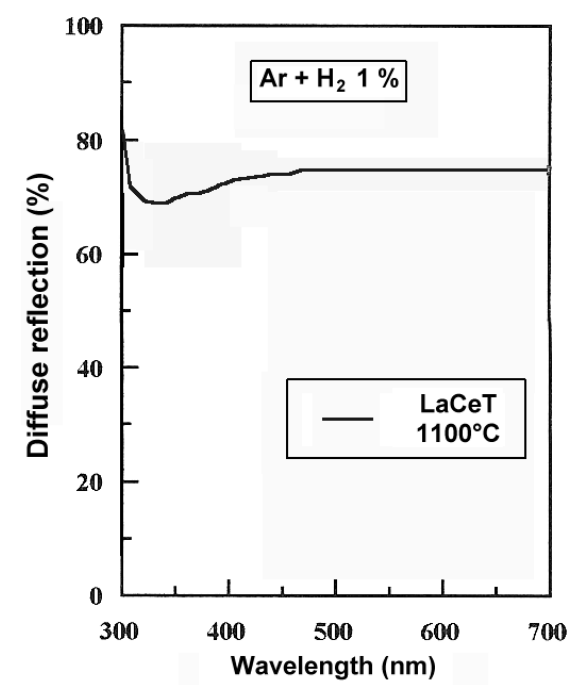

Fig. 6. Diffuse reflection spectra of LaCeT prepared without flux at $1100^{\circ} \mathrm{C}$ under $\mathrm{Ar}+\mathrm{H}_{2} 1 \%$

Moreover their emission intensity and their transfer efficiency keep the same values with and without flux, considering the measuring error. The diffuse reflection coefficients and the intensity have been determined under a $340 \mathrm{~nm}$ excitation, which is the wavelength of the most intense cerium emission broadband $[5,10]$.

\section{DISCUSSION}

This study shows that two parameters have a considerable importance on the LaCeT grain growth : the initial quantity of flux introduced and the constituent cation of the flux.

Considering the complexity of the phenomena occurring during this mechanism, the influence of each parameter can not be separated : they should be taken into account in all of the steps of the reaction.

Actually, these parameters influence the wettability of the LaCeT powder by the liquid, the solubility of the solid phase into the liquid, the viscosity of the liquid...

In that work, the constituent cation of the flux has been found to have a significant effect on the LaCeT grain growth. The cation diameter is supposed to be the key parameter in that phenomenon. In fact, the flux alkaline cation can diffuse into the phosphate grains as the TL experiment show. This diffusion will be all the easier since the cation is smaller.

Moreover, the diffusing element concentration will be the higher near the surface of the grains, allowing to modify the phosphate physico-chemical properties. As a result, first the grain growth kinetic and second, the phosphate solubility into the liquid phase will be modified. Then, these consequences may modify the dissolution kinetic during the ripening step. 
The fluxes action on the LaCeT particles morphology seems to be similar to a liquid phase sintering mechanism which would happen in three steps :

- Formation of a liquid phase $\left(\mathrm{LiPO}_{3}\right.$ which melting point is $\left.600^{\circ} \mathrm{C}\right)$.

- Dissolution of a little quantity of $\mathrm{LaPO}_{4}$ in the liquid phase (reaction between $\mathrm{LaPO}_{4}$ and $\mathrm{LiPO}_{3}$ ). Then precipitation of $\mathrm{LaPO}_{4}$.

- Ostwald ripening.

Finally the results shown in the section 3 imply that, in our experimental condition, with and without flux use, the diffuse reflection spectra do not show any difference and the emission intensity remains the same. However an increase was expected. In fact the sample studied was compacted with a quartz window, showing a regular surface with or without flux. But in real condition of deposit, a sample has a smoother surface when it is prepared with flux than without flux. Then we expect to have an increase of the fluorescence emission intensity with a powder prepared with flux.

\section{PERSPECTIVES}

An other study on the precursor-flux interaction is currently studied with an aluminate phosphor. The precursor has also been synthesized by the Rhodia society. Figure 7 shows the morphology of the precursor powder.

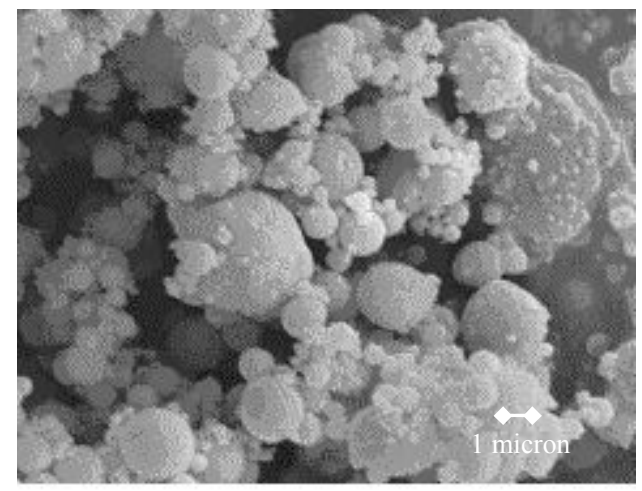

Fig. 7. SEM micrograph of the aluminate precursor

From this precursor with spherical-shaped grains, phosphor powders have been synthesized. Thanks to different fluxes, we managed to produce powder particles with spherical shape or hexagonal plate shape and with adjustable mean diameter from 1 to $6 \mu \mathrm{m}$ as shown on Fig. 8 .

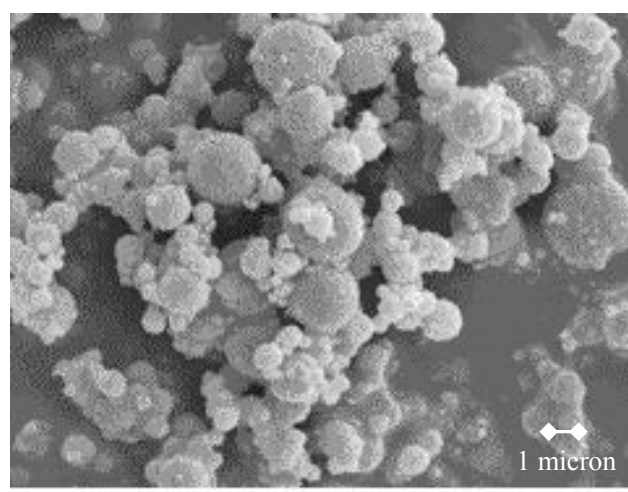

(a) Aluminate phosphor powder without flux Magnification x 5000

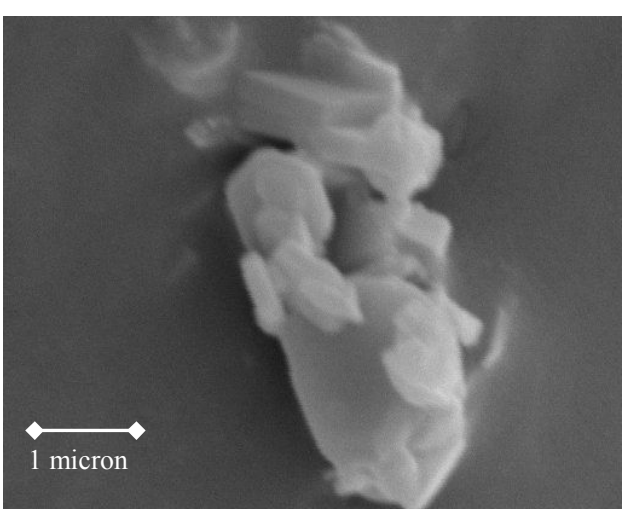

(b) Aluminate phosphor powder with a flux Magnification x 15000

Fig. 8. SEM micrograph of the aluminate with (a) and without flux (b) 


\section{CONCLUSION}

This study shows that adding some determined fluxes with an adapted quantity allows to control the powder morphology in order to obtain grains with desired shape and size : sphereshaped, parallelepiped-shaped, or hexagonal-plate-shaped.

The action of the fluxes on the LaCeT phosphor seams to be a liquid-phase-sintering-like mechanism with an Ostwald ripening.

Further experiments have to be undertaken in order to understand the action of fluxes on those phosphor powders and especially to verify the effect of the flux viscosity, the phosphor solubility into the fluxes and the wettability of the powder particles with the fluxes, all that at the firing temperature.

\section{REFERENCES}

1. S. Oshion K. Kitamura, T. Shigeta, S. Horii, T. Matsuoka, S. Tanaka, H. Kobayashi, Journal of the electrochemical society 146 (1999) 392-399

2. Y.C. Kang, E.J. Kim, D.Y. Lee, H.D. Park, High brightness $\mathrm{LaPO}_{4}: \mathrm{Ce}, \mathrm{Tb}$ phosphor particles with spherical shape, J. of Alloys and Comp. 347 (2002) 266-270

3. I.W. Lenggoro, B. Xia, H. Mizushima, K. Okuyama, N. Kijima, Synthesis

of

LaPO4:Ce,Tb phosphor particles by spray pyrolysis, Materials Letters 50 (2001) 92-96

4. S. Shionoya, W. M. Yen, Phosphor Handbook (1998)

5. M. Junker, Thesis ENSM-SE (1995)

6. S. Erdei, F.W. Ainger, D. Ravichandran, W.B. White, L.E. Cross, Preparation of $\mathrm{Eu} 3+: \mathrm{YVO}_{4}$ red and $\mathrm{Ce}^{3+}, \mathrm{Tb}^{3+}: \mathrm{LaPO}_{4}$ green phosphors by hydrolyzed colloid reaction (HCR) technique, Materials Letters 30 (1997) 389-393

7. L.S. Joung, J.J. Eun, Patent $n^{\circ} 2808799$ Samsung SDI CO LTD-KR

8. L. Amathieu, Thesis Aix Marseille III (1985)

9. C.H. Lo, J.G. Duh, B.S. Chiou, C.C. Peng, L. Ozawa, Materials chemistry and physics 71 (2001) 179-189

10. B. Di Bartollo, Optical interactions in solids, John Willey and Sons (New-York) (1968)

11. D. Ehrentraut, M. Pollnau, J. of Crystal Growth, 234 (2002) 533-538

12. P. Iacconi, M. Junker, B. Guilhot, D. Huguenin, Thermoluminescence of mixed rare earth phosphate powder $\mathrm{La}_{1-\mathrm{x}-\mathrm{y}} \mathrm{Ce}_{\mathrm{x}} \mathrm{Tb}_{\mathrm{y}} \mathrm{PO}_{4}$, Optical Materials, 17 (2001) 409-414 